\title{
Ensino religioso nas escolas estaduais do Rio de Janeiro: implicações para o ensino de ciências/biologia
}

\author{
Teaching of religion in the State of Rio de Janeiro public \\ schools: implications to science and biology teaching
}

\author{
Sandra Escovedo Selles ${ }^{1}$. Luís Fernando Marques Dorvillé ${ }^{2}$. \\ Leandro Vahia Pontual ${ }^{3}$
}

\begin{abstract}
Resumo: Este trabalho examina implicações e desafios ao ensino de Ciências e Biologia emergentes da implantação de lei obrigando o ensino religioso na forma confessional no estado do Rio de Janeiro. Utilizamos como fonte cartas dos leitores de O Globo, além de outros pronunciamentos da mídia e textos acadêmicos. A polêmica do ensino religioso nas escolas públicas brasileiras aparece associada a novos elementos, incluindo pela primeira vez discussões ligadas não apenas a cidadania e liberdade religiosa, mas também ao confronto entre os pontos de vista criacionista e evolucionista, relativamente novo no Brasil, com enorme potencial de crescimento. Este cenário resulta da formação de novas alianças entre grupos religiosos disputando o espaço público com defensores da laicidade. Diante disso, reforçamos a importância das atividades de divulgação científica e de demarcação da natureza da Ciência, sendo especialmente importantes nesse sentido as contribuições da Filosofia e História da Ciência.
\end{abstract}

Palavras-chave: Evolução. Ensino de ciências. Ensino de biologia. Ensino religioso. Criacionismo.

\begin{abstract}
This work aims to investigate the implications and challenges to Science and Biology teaching that arose from the implementation of a State law in Rio de Janeiro, Brazil, which made confessional religious teaching mandatory in public schools. As a source, we have employed the readers' letters section in the newspaper O Globo, supplemented by other media statements and academic works. The controversy of religious teaching in Brazilian public schools shows to be associated with new elements, including disputes related not only to citizenship and religious freedom, but also to the debate between creationist and evolutionist views, a relatively new confrontation in Brazil with a huge growth potential. This setting comes from new alliances between religious groups disputing in the public space against defenders of secularity. On face of it, we reinforce the importance of promoting scientific dissemination and the philosophical demarcation of Science in the classroom, with the special contributions of Philosophy and History.
\end{abstract}

Keywords: Evolution. Science teaching. Biology teaching. Religious teaching. Creationism.

\footnotetext{
${ }^{1}$ Universidade Federal Fluminense (UFF), Faculdade de Educação, Departamento Sociedade, Educação e Conhecimento, Niterói, RJ, Brasil. E-mail: <sandra.escovedo@cnpq.br>.

${ }^{2}$ Universidade do Estado do Rio de Janeiro (UERJ), Faculdade de Formação de Professores, Departamento de Ciências, São Gonçalo, RJ, Brasil.

${ }^{3}$ Centro Universitário Anhanguera, Niterói, RJ, Brasil.
} 


\section{Introdução}

Embora não se apresente como uma questão particularmente nova na história da educação brasileira, a polêmica sobre o ensino religioso nas escolas públicas ganhou certamente novo ímpeto a partir da década de 1990. A institucionalização legal do ensino religioso nesses espaços e seu financiamento público se deram em um momento no qual, segundo Cavalieri (2007), cada vez mais grupos religiosos passaram a ocupar espaços de destaque no cenário político e social. A posição do Rio de Janeiro, nesse sentido, é bastante emblemática, como um exemplo das contradições e tensões produzidas na implantação desse processo. Isso pode ser explicado tanto pelo protagonismo de alguns dos atores locais envolvidos, quanto pelos desdobramentos na esfera institucional e no cotidiano escolar que acompanharam sua implantação.

Em nosso país, muitos embates têm sido travados há tempos em torno da legitimação do ensino religioso nas escolas públicas, em uma história tensionada inicialmente apenas entre a Igreja Católica e o Estado. Desde que a primeira constituição republicana, fundada sob o ideário liberal, proibiu o ensino religioso nas escolas oficiais, os setores eclesiásticos católicos passaram a se organizar para "restaurar a Igreja e seus valores na vida pública brasileira e na educação em particular” (DAVILA, 2006, p. 255). De fato, a legislação dos anos 1930 reaproximou a Igreja e o Estado, e na Constituição de 1934 o ensino religioso passou a ser disciplina obrigatória com matrícula facultativa. Desde então, embora o estado tenha se mantido declaradamente laico, o ensino religioso vem marcando presença em todas as constituições federais brasileiras, inclusive na de $1988^{4}$.

A questão do ensino religioso retorna nos debates sobre a Lei de Diretrizes e Bases da Educação Nacional de 1996, culminando na incorporação ao seu texto de um artigo ${ }^{5}$ que traz muita ambiguidade, sobretudo quanto à manutenção do caráter facultativo da matrícula e a atribuição do ônus para os cofres públicos. De acordo com alguns autores (CARNEIRO; CONTINS, 2006; CURY, 2004) a ambiguidade existente na lei 9.475/97 se refere não apenas à omissão da questão do ônus financeiro, mas também porque: (i) o ensino religioso passa a ser entendido e definido como integrante da formação do cidadão, o que fere o direito constitucional à diferença e à liberdade; (ii) os procedimentos para o ensino religioso passam a ser tratados de forma descentralizada, pois o artigo atribui ao poder estatal a incumbência de regulamentá-lo, definindo normas para habilitação e admissão dos professores desta disciplina; (iii) a definição dos conteúdos do ensino religioso à entidade civil, integrada pelas diferentes denominações religiosas é considerada extremamente complexa pela própria dificuldade de definir o que constituiria tal (ou tais) entidade(s) civil (ou civis). Segundo Cury (2004), o princípio constitucional de laicidade fica comprometido no caráter "facultativo" expresso no conteúdo do artigo. Cunha

\footnotetext{
${ }^{4}$ Art. 210, \10: “O ensino religioso, de matrícula facultativa, constituirá disciplina dos horários normais das escolas públicas de ensino fundamental” (CURY, 2004, p. 185).

${ }^{5}$ A primeira redação do art. 33 da segunda Lei de Diretrizes e Bases da Educação Nacional determinava que o ensino religioso seria oferecido como disciplina "sem ônus para os cofres públicos", podendo ser oferecida "em caráter confessional ou interconfessional”. Várias autoridades religiosas, em especial as católicas, pressionaram a presidência da República e o artigo foi alterado, produzindo a lei $\mathrm{n}^{\circ} 9.475 / 97$, considerada ainda de caráter ambíguo (CUNHA, 2006; CURY, 2004).
} 
(2006) destaca também que a supressão do interconfessionalismo ${ }^{6}$ como a modalidade de Ensino Religioso expressamente reconhecida, forneceu um apoio simbólico aos grupos religiosos que se opunham a essa abordagem. Deste modo, como observam Giumbelli e Carneiro (2004) abriu-se caminho em vários Estados brasileiros para uma interpretação mais restrita da lei, instituindo o caráter confessional do ensino religioso, como no estado do Rio de Janeiro.

O governador do Estado do Rio de Janeiro Anthony Garotinho sancionou no dia 14 de setembro de 2000 a lei 3.459 que obriga o ensino religioso na rede pública estadual na forma confessional. O projeto original era do ex-deputado Carlos Dias (do PPB) ${ }^{7}$, que facultava aos pais o direito de escolher a orientação religiosa a ser lecionada aos filhos. Para se adequar à lei, segundo o autor do projeto, seriam necessários três mil profissionais contratados por concurso público. Nessa mesma época, o governador, que se declara evangélico ${ }^{8}$, afirmou em nota oficial que a lei é uma forma de tirar os jovens da violência e das drogas, fato também ressaltado por D. Eugênio de Araújo Sales (1920-2012), Arcebispo do Rio de Janeiro à época, no espaço “Opinião" do jornal O Globo. Quase em coro com o governador, D. Eugênio assim se pronunciou:

Ele [Garotinho] e os parlamentares que votaram favoravelmente a essa lei merecem elogio e apoio dos homens de bem. Possibilitar o ensino religioso confessional às novas gerações é ir às raízes da violência, da corrupção e da imoralidade, fruto do desconhecimento de Jesus, ausência do temor de Deus. (SALES, 2000, p. 7).

Essa aliança heterogênea entre o que Cunha (2012) classifica como o populismo político e o conservadorismo religioso recoloca a polêmica do ensino religioso na escola pública associada a novos elementos. Embora a questão evolutiva não seja mais um tema contestado pela doutrina católica ${ }^{9}$ (SCOTT, 2004) a aliança estratégica com denominações religiosas evangélicas visando a ampliação da sua influência no espaço público, trouxe pela primeira vez ao cenário da educação pública brasileira questões ligadas ao debate entre os pontos de vista do criacionismo

\footnotetext{
${ }^{6}$ No ensino de caráter confessional está explícita uma opção religiosa, seja do aluno, seja dos responsáveis, enquanto no interconfessional várias interpretações religiosas são apresentadas aos alunos sem opção declarada por uma delas.

${ }^{7}$ Segundo Cunha (2012) e Giumbelli e Carneiro (2004), o ex-deputado Carlos Dias era direta e publicamente vinculado a autoridades e grupos da Igreja Católica no Rio de Janeiro e foi com o apoio deles que apresentou seu projeto de lei.

${ }^{8}$ Neste trabalho optamos como Mafra (2001), pelo termo “evangélico" em sua acepção mais abrangente, englobando todas as denominações religiosas provenientes da Reforma, embora estejamos cientes do universo de posições encontradas no protestantismo.

${ }^{9}$ Em 1996, por exemplo, a Igreja Católica, na figura do Papa João Paulo II, defendeu a evolução do homem a partir de outras espécies de primatas, reservando, porém, a intervenção divina para a criação da alma humana, a qual teria entrado nos corpos de nossa espécie apenas ao final desse processo. Em 2014 o Papa Francisco afirmou que a Teoria da Evolução e o Big Bang são reais e criticou a interpretação das pessoas que leem o Gênesis, livro da Bíblia, achando que Deus "tenha agido como um mago, com uma varinha mágica capaz de criar todas as coisas” (VEIGA; BRANDÃO, 2014, p. 22).
} 
e do evolucionismo. Diante da defesa do ensino do criacionismo nas escolas públicas por parte desses grupos religiosos em franca expansão no cenário religioso nacional (JACOB et al., 2003), tais questões apresentam um enorme potencial de crescimento no Brasil.

O acompanhamento dessa polêmica pode ser feito através dos diferentes meios de comunicação, em particular pelos jornais. Em torno das matérias por eles veiculadas forma-se uma rede discursiva que pode oferecer material importante para o estudo dos sentidos que estes processos produzem na sociedade. Neste trabalho utilizamos como campo empírico principal o estudo das matérias e cartas dos leitores de O Globo sobre as polêmicas relacionadas à implantação do ensino religioso nas escolas públicas do Rio de Janeiro, complementadas por outros pronunciamentos na mídia e textos acadêmicos.

A análise empreendida pretendeu compreender como o jornal e seus leitores se posicionaram em relação à aprovação da lei; que argumentos apresentaram a favor e contra ela; quais questões foram levantadas; como as questões do criacionismo versus evolucionismo foram tratadas; e, finalmente, se os leitores mencionaram necessidades e problemas cotidianos em relação às aulas de Ciências e Biologia. A partir dessa análise esperamos apontar alguns dos desafios e implicações para o ensino de Ciências e Biologia.

\section{Metodologia}

O conceito de rede discursiva, segundo Fry (2005), tem origem nos trabalhos de Kittler (1990), referindo-se ao conjunto de discursos produzidos na mídia, nos meios acadêmicos e nos documentos governamentais em torno de um determinado fato social, levando em consideração o contexto social de sua produção. Os principais objetos empíricos de investigação que utilizamos nesse trabalho foram as cartas dos leitores de $O$ Globo ${ }^{10}$. Para dialogar com elas, na perspectiva da rede discursiva, era imprescindível também fazer um levantamento das matérias (reportagens, colunas e notas) relacionadas ao ensino religioso, evolucionismo e criacionismo.

O levantamento das cartas dos leitores e das matérias do jornal foi feito a partir de quatro grupos de palavras chave: "ensino religioso + religião", "ensino religioso + criacionismo", "ensino religioso + religião" e, "ensino religioso + evolucionismo". Como apenas em 1997 a LDB passou a ter destaque no jornal, o intervalo de tempo investigado foi de $1^{\circ}$ de janeiro de 1997 a 31 de dezembro de 2005.

\section{Apresentando e construindo a Rede Discursiva}

Foram encontrados 102 registros, sendo 67 no formato de matérias e 35 na forma de carta dos leitores. As matérias foram analisadas quanto à tendência de seus conteúdos para que pudessem ser classificadas em três grupos de respostas: "a favor", quando a linha de argumentação era favorável à implantação do ensino religioso confessional; "contra", quando a apresentação da matéria se declarava contrária à sua implantação; e um terceiro grupo, que acomodava as matérias que possuíam conteúdo exclusivamente informativo, sem opinião ou

\footnotetext{
${ }^{10}$ Optamos por esse periódico em virtude de sua grande circulação e relevância no estado do Rio de Janeiro.
} 
tendência expressa (Figura 1). Todas as cartas foram distribuídas de forma semelhante, com uma importante diferença: para elas não utilizamos o terceiro grupo, pois a ideia da seção "Carta dos Leitores" é justamente expor opiniões (Figura 2).

Em 11 de janeiro de 1997, a matéria intitulada "Igreja e escola na letra de Cecília Meireles", destacava a importância da luta pela laicidade no contexto pouco conhecido do caráter combativo da escritora. A reportagem trazia ainda um breve histórico da disputa por espaço na escola pública, travada a partir dos anos 1930, apontando a força política reconquistada pela Igreja Católica com o advento da fundação da Liga Eleitoral Católica.

$\mathrm{Na}$ mesma direção, no dia 22 de abril, o jornalista Ricardo Boechat relatou um movimento muito semelhante de demonstração de força política da Igreja Católica. O texto dizia que: "Embora às turras, o Planalto e a CNBB estão para dar as mãos...". Isto porque o então Presidente da República, Fernando Henrique Cardoso, tentava ganhar a confiança da Igreja Católica, após desencontros com Dom Lucas Moreira Neves, em relação a temas como a Reforma Agrária e a privatização da Vale do Rio Doce. Segundo as palavras do próprio Dom Lucas, a Igreja vinha fazendo um trabalho de convencimento para corrigir o que considerava uma injustiça.

O artigo do filósofo José Arthur Giannotti (GIANNOT'TI, 1997), Senso religioso e contra-senso político foi o único espaço no jornal, no ano de 1997, para uma defesa mais extensa da oposição ao ensino religioso na escola pública. $\mathrm{O}$ autor destacou que a diversidade das experiências religiosas, quando vira matéria em discussão, deixa a fé de lado e passa a mover-se em um plano exclusivamente racional. Assim, a escola não seria o lugar ideal para se ensinar religião.

Figura 1. Matérias do jornal O Globo sobre a aprovação do Ensino Religioso (ER) em escolas públicas no Estado do Rio de Janeiro, no período de 01/01/1997 a 31/12/2005

Matérias sobre Ensino Religioso entre os anos 1997 e 2005

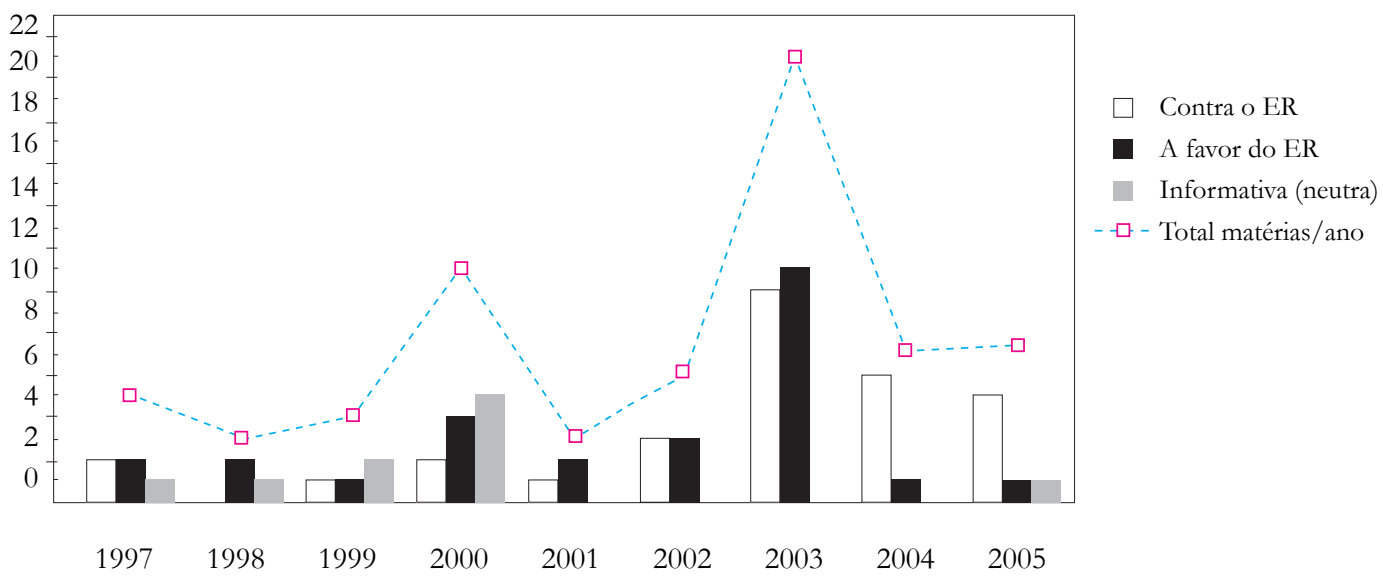

Ano

Fonte: elaborado pelos autores. 
Figura 2. Cartas dos leitores de $O$ Globo sobre a aprovação do Ensino Religioso (ER) em escolas públicas no Estado do Rio de Janeiro no período de 01/01/1997 a 31/12/2005

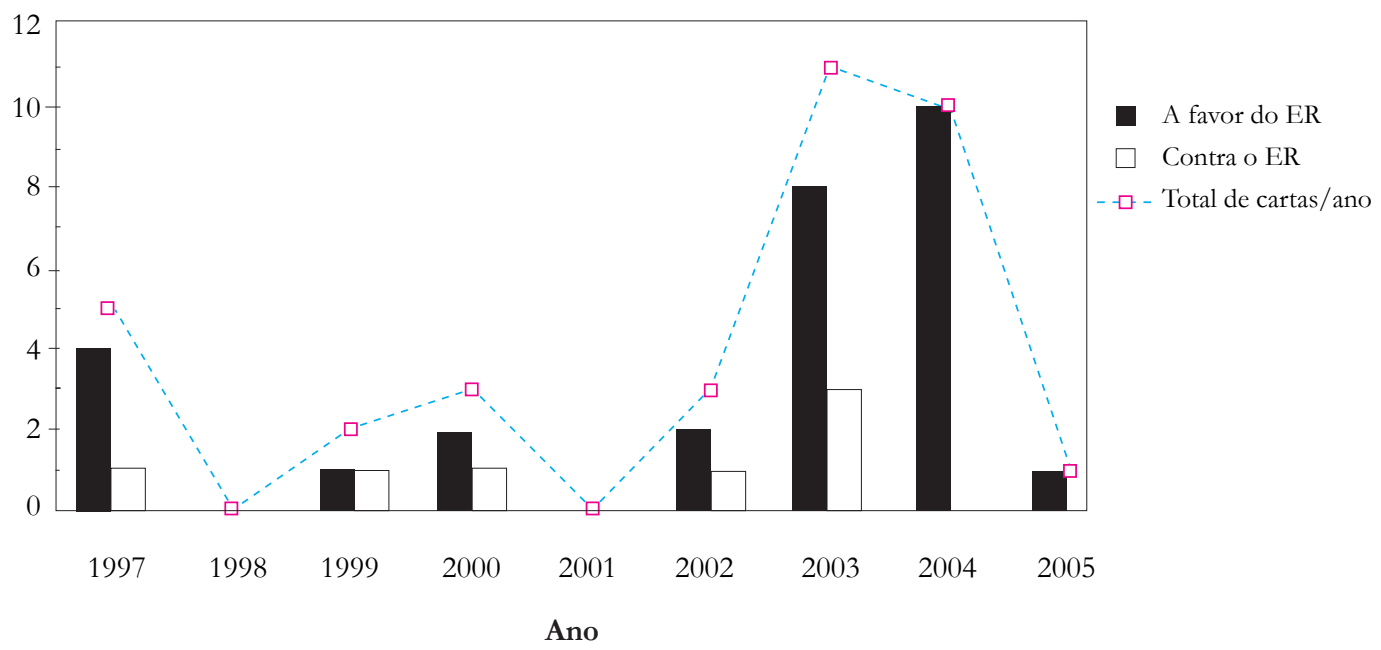

Fonte: elaborado pelos autores.

A partir dessa data, a defesa do ensino religioso encontra espaço generoso no jornal, através dos editoriais Ensino religioso e a Constituição de Dom Lourenço de Almeida Prado (PRADO, 1997), então reitor do Colégio São Bento, e de Dom Eugênio Sales (SALES, 1997), Educar para salvar. Em seu artigo, marcado pelo tom de defesa da pluralidade e da liberdade e pelo anti-esquerdismo, Dom Lourenço caracterizou a LDB como "confusa e conflitante", sendo "marcada pelo estatismo esquerdizante". Como uma tônica do estilo político de todo o editorial, Dom Lourenço afirmou que:

Não há ninguém que reclame mais pelos direitos humanos que o bandido assassino encarcerado. Reclama da comida; reclama da superlotação, como se ele mesmo não fosse um contribuinte para ela. [...] Não há também ninguém mais veemente no zelo pela liberdade pessoal, pela neutralidade estatal que o esquerdista totalitário. Sobretudo em relação ao ensino religioso nas escolas públicas. (PRADO, 1997, p. 7).

Reforçando o coro, Dom Eugênio Sales defendeu que a educação deve ser prioridade em nosso país, com importância particular para o ensino confessional, sempre pautado na importância da promoção dos valores morais em uma sociedade em desagregação:

Para isso é de fundamental importância o ensino religioso, não só nas paróquias, responsabilidade exclusiva da Igreja, mas também nas escolas, dever 
compartilhado pelo poder público. Somente o aprendizado e a vivência de uma doutrina transcendente dão uma dimensão verdadeiramente humana. Permite o crescimento de virtudes indispensáveis a uma existência honesta, pacífica e fecunda, ao serviço da pátria e do próximo. (SALES, 1997, p. 7).

Importante perceber que em todos os três editoriais o ensino religioso é defendido sem menção alguma à diversidade de crenças, assumindo como natural que se trate da defesa dos valores da Igreja Católica. Nesse primeiro momento, a construção da rede discursiva de apoio ao ensino religioso não passa ainda pelos argumentos de outras denominações religiosas.

A repercussão das matérias "a favor" do ensino religioso não tardou em surtir efeito, traduzindo-se no predomínio das cartas de leitores a seu favor. Os argumentos variaram da primazia da religião sobre todas as outras esferas humanas à defesa da promoção dos valores morais associados ao seu ensino. Houve também forte apoio ao editorial de Dom Lucas, a partir de argumentos baseados na defesa da democracia e da pluralidade, contra um Estado que deseja impor o ensino laico.

A única voz destoante veio curiosamente de um religioso protestante, o Reverendo Jouberto Heringer, professor do Seminário Presbiteriano do Rio de Janeiro:

Como ministro da Igreja Presbiteriana do Brasil e, portanto, ligado ao protestantismo histórico, causa-nos não somente estranheza, mas total repúdio à ideia de ministrar ensino nas escolas públicas ou subvencionadas pelo Governo. O Estado é laico e distinto da religião desde a primeira Constituição republicana. O motivador da crença que origina a religião é a fé, e este é um valor subjetivo de identidade e individualidade de cada pessoa, que se expressa fisicamente na sociedade em comunidades de relativa afinidade de crença. (HERINGER, 1997, p. 6).

\section{Ponto de inflexão e redirecionamento dos debates}

O ano de 1998 foi marcado por dois fatos significativos na constituição dessa rede discursiva, caracterizando-o como um ponto de inflexão: em primeiro lugar em virtude do silêncio dos leitores, que não se manifestaram em momento algum (Fig. 2). Em segundo, pelo aparecimento de novas vozes e discursos nessa rede. De fato, a única movimentação significativa para o contexto desta investigação, neste ano, foi a manifestação das religiões não-católicas perante os membros do Conselho Nacional de Educação (CNE). Os evangélicos, espíritas e outros exigiram o respeito à lei aprovada pelo Congresso que dispunha sobre o ensino religioso não-confessional (evitando privilégios a qualquer religião específica). Isto porque foi constatado por unanimidade no CNE que o parecer do conselheiro, o padre jesuíta Kuno Paulo Rhoden (TAVES, 1998), privilegiava o ensino da religião católica em detrimento das demais.

Pontos de inflexão como esse não correspondem a momentos de mudança de posição do jornal, mas a períodos de menor ênfase ao tema abordado diante do rearranjo de posições característico de um período de mudanças como o enfrentado nesse momento. Enquanto os debates se multiplicavam no interior do CNE, revelando a complexidade das questões envolvidas, o jornal reduziu sua ênfase sobre o tema. 


\section{Novos tempos, novas alianças}

Em 1999 as matérias passaram a tratar a questão do ensino religioso sob uma ótica pragmática. As defesas genéricas da liberdade e da ausência de imposições tiveram que lidar então com suas consequências práticas, difíceis de serem equacionadas em um cenário religioso bem mais complexo do que no passado e com a oposição de setores conservadores a qualquer gasto adicional para sua implantação, ainda que para garantir alguns dos princípios defendidos anteriormente. Dom Eugênio Sales e Dom Lourenço de Almeida Prado mantiveram a defesa do ensino confessional, mas o próprio jornal O Globo, em editorial, afirmou que

Se o Estado vai pagar a professores comprometidos com esta ou aquela crença, deveria, então, pagar a mais de um professor - e eis o custo das escolas aumentado, o que não parece muito viável nos tempos de agora. Talvez fosse mais simples (e mais justo) simplesmente criar disponibilidades de espaço e de tempo, no dia-a-dia das escolas, para que as diversas confissões religiosas apresentem a sua mensagem - tomando o cuidado de não obrigar ninguém a ouvir a pregação que não quer ouvir. (KAMEL, 1999, p. 6).

Embora mantivesse generoso espaço em seu editorial para a exposição do pensamento da ala mais conservadora do clero, o jornal deixou clara a sua posição de aceitar o ensino religioso na escola pública desde que este não resultasse em qualquer ônus para o Estado. Duas posições que não são exatamente iguais e que ao longo do processo se afastaram mais em alguns momentos, sem nunca necessariamente romperem.

Na matéria intitulada Sobre a necessidade de um Estado laico (GOMES, 1999, p. 7), o psicólogo Adelmo Senra Gomes apontou para os perigos da desigualdade, injustiça e desrespeito às diferenças que vêm ocorrendo em instituições de ensino norte-americanas em virtude da atuação de movimentos cristãos antievolucionistas. É a primeira vez que a questão do criacionismo e sua relação com o ensino de Ciências ganha espaço nessa discussão, ainda que de modo muito breve. $\mathrm{O}$ autor destacou ainda que em nome do respeito à diferença os alunos não podem ser obrigados a receber aulas confessionais de um professor de outra religião.

A conclusão de que o ensino religioso pode gerar conflitos éticos diante da diversidade religiosa existente em nosso país também dificultou sua regulamentação no CNE, que delegou as questões de fixação dos conteúdos, habilitação e admissão de professores aos diferentes sistemas de ensino, assim como a definição dos conteúdos curriculares que orientam a formação dos professores, aos governos locais (CURY, 2004). Por sua vez, no ano de 1999 as opiniões dos leitores focaram menos nas questões de implantação e problemas provenientes destas e mais sobre a relação custo/benefício do ensino de mais uma disciplina.

Em 14 de setembro desse ano, o deputado Carlos Dias apresentou seu projeto de lei sobre o ensino religioso na Assembleia Legislativa do Rio de Janeiro que propunha a ampliação da oferta da disciplina para todos os níveis da educação básica (GIUMBELLI; CARNEIRO, 2004). Além disso, previa que os professores fossem do quadro do magistério público estadual e credenciados por autoridade religiosa, autorizando o poder público a abrir concurso específico para esse propósito. Embora diretamente ligado à Igreja Católica, esse deputado articulou politicamente para fortalecer os interesses que representava e obteve também o apoio do governador 
Anthony Garotinho e da Ordem dos Ministros Evangélicos do Brasil (OMEB) em todo o processo (MENDONÇA, 2012). Em tempos de fraturas internas e inúmeras dificuldades práticas na implementação da proposta de ensino religioso confessional, a realização de novas alianças em torno de causas comuns foi fundamental para a concretização da proposta confessional.

A entrada em cena desse projeto de lei e todos os debates que cercaram a sua aprovação resultaram, no ano 2000, em um número de matérias bem superior ao dos anos anteriores. O colunista Elio Gaspari, por exemplo, destacou que, aliado ao gasto da federação com o ensino religioso adiciona-se um rombo da ordem de $\mathrm{R} \$ 2,3$ bilhões anuais que a Previdência deixa de arrecadar de instituições filantrópicas, nas quais se incluem 1.282 escolas católicas, conta esta paga por todos os contribuintes, independente de seus credos (ou ausência de tais) (GASPARI, 2000).

Aprovado em plenário, o projeto foi sancionado como a lei $n^{\circ} 3.459$ pelo governador em 14 de setembro de 2000. Segundo Carlos Dias, “[...] mesmo que as turmas sejam pequenas, deverá haver um professor para cada tipo de credo [...]” (VILHENA, 2000, p. 21), o que foi contestado pela própria Coordenadora de Ensino Religioso da Secretaria de Educação, Ediléia da Silva, que afirma, na mesma reportagem, que o governo não teria como oferecer aulas para todos os tipos de credos, nem poderá optar por algum deles.

Ocorreram dissensões a respeito do enfoque a ser assumido por esse ensino no interior de grupos anteriormente unidos, sendo a lei questionada principalmente por seu caráter confessional, como pode ser percebido nas palavras de Padre Roque Zimmerman, o mesmo deputado a alterar o artigo 33, garantindo o financiamento público do ensino religioso: "O ensino religioso deve ser tratado do ponto de vista antropológico como fenômeno cultural" (MATHEUS, 2000, p. 15). O deputado Carlos Minc foi um dos principais opositores do caráter confessional da lei, questionando sua legitimidade. Para ele, o ensino confessional é doutrinário, e por ter o conteúdo subordinado às autoridades religiosas, não se encaixa no que propõe a LDB. Todos os movimentos contrários à lei, como o Sindicato Estadual dos Profissionais de ensino (SEPE), Movimento Inter-religioso do Rio de Janeiro, Instituto Superior de Estudos da Religião (ISER) e mesmo, como vimos, alguns setores da Secretaria Estadual de Educação, ressaltaram que contratar professores de ensino religioso para as 1.924 escolas estaduais seria inviável, principalmente diante do grande déficit de professores já existente.

O jornal manteve o espaço para os editoriais de duas autoridades eclesiásticas, agora substituindo Dom Lourenço por Dom Filippo Santoro, bispo auxiliar do Rio de Janeiro com atuação na Pastoral dos Políticos Católicos, a mesma de que fazia parte o deputado Carlos Dias. Segundo Cunha (2012) seu protagonismo foi notório na ação decisiva para a aprovação da lei na Assembleia Legislativa do Estado do Rio de Janeiro. Fazendo a defesa do caráter confessional dessa nova disciplina, Dom Filippo argumentou em seu editorial que se o ensino religioso fosse reduzido a "puros elementos de Antropologia, [...] sob esse nome poderiam ser colocadas as coisas mais diversas e contrastantes, que acabariam confundindo ou mesmo desviando a religiosidade do aluno" (SANTORO, 2000, p. 5). Sob essa ótica, prossegue na mesma página: "Marx e Freud com certeza ganhariam um concurso público para o ensino religioso; mas, com pleno direito, as instituições religiosas negariam o mandato a quem tivesse o objetivo de destruir ou alterar uma determinada religião" (SANTORO, 2000, p. 5). O editorial de Dom Eugênio Sales seguiu na defesa do ensino confessional. Duas cartas manifestaram-se a favor do ensino religioso na defesa da formação dos jovens contra a desagregação moral e outra foi contra, tomando por base a visão do ateísmo como um problema a ser corrigido. 


\section{Novo ponto de inflexão, fundamentalismos e criacionismos}

Diante do protagonismo obtido pela insólita aliança entre setores ligados à arquidiocese e seu desafeto político, Anthony Garotinho, o jornal O Globo passou em 2001 por novo período de inflexão, que se traduziu novamente na ausência de manifestações de seus leitores na seção de cartas, possivelmente fruto de matérias que gerassem poucas polêmicas ou discussões. Nos anos seguintes terão cada vez mais espaço no jornal as críticas a aspectos da implantação do ensino religioso no Rio de Janeiro, mantendo simultaneamente a defesa da necessidade do ensino confessional nos editoriais das autoridades católicas. O resultado pode sugerir um equilíbrio na orientação das matérias contra e a favor do ensino religioso, mas na verdade as matérias versam sobre questões diferentes: as a favor, sobre o princípio, e as contra, sobre o modo como ele foi implantado.

Essa "nova" orientação pode ser explicada não apenas pela oposição ao governo de Rosinha Matheus, esposa de Garotinho e sua sucessora, como também pelo protagonismo que passaram a ter em seu governo os grupos evangélicos conservadores. Estes passaram a defender com cada vez mais desenvoltura sua agenda fundamentalista, com temas como a defesa do criacionismo e a leitura da Bíblia na sala de aula, exatamente como ocorre em várias escolas públicas nos Estados Unidos desde os anos 1920 (LARSON, 2003). Os resultados dessas matérias não deixaram de se fazer sentir nas cartas dos leitores, que passaram na segunda metade do gráfico a criticar fortemente o ensino religioso implantado (Fig. 2), como se este não fosse o resultado final do mesmo processo que antes muitos aprovavam. Cabe destacar que, para o grande público, o projeto de implantação do ensino religioso no Estado havia se transmutado em obra apenas de políticos evangélicos, visão esta que ainda persiste e que o presente artigo busca desconstruir.

Em setembro, o novo arcebispo, dom Eusébio Oscar Scheid, realizou a peregrinação política pela cidade. Visitou o então governador Garotinho e, depois, reuniu-se com o ex-presidente da Assembleia Legislativa, Sérgio Cabral Filho, tentando garantir, junto aos políticos, um trabalho em conjunto entre as autoridades civis e eclesiásticas para pôr em prática tanto a forma de preparação quanto a realização do concurso para os professores de ensino religioso (PESSOA, 2001).

Em 2002, ano de eleição, as matérias sobre o ensino religioso se concentraram no mês de março. O modo como se deu a implantação da disciplina de ensino foi cercado de protestos de vários setores, exceto da Igreja Católica, satisfeita com seu caráter confessional e financiado pelo poder público, como evidenciado nos editoriais de Dom Eugênio (SALES, 2002) e do Padre Jesus Hortal, reitor da PUC-Rio (HORTAL, 2002).

Como uma marca dos novos tempos, o deputado Alessandro Calazans (PV), evangélico que frequentava então a Igreja da Graça, procurou tornar obrigatória a leitura diária de um trecho da Bíblia no início das aulas nas escolas públicas do Estado. Aprovada em primeira votação, a lei foi posteriormente arquivada (HIDALGO; BERTOL, 2002). A notícia logo provocou fortes reações entre os leitores. O principal argumento foi o da violência resultante da adoção dessa medida para as famílias não-cristãs cujos filhos frequentassem essas escolas.

A partir da posse de Rosinha Garotinho, em 2003, multiplicaram-se as reportagens contra o modelo de ensino religioso implantado no Rio de Janeiro. Matérias sobre o perigo do fundamentalismo religioso, demonstrações de falência do ensino público estadual e as várias 
disputas travadas na Assembleia Legislativa e nos tribunais geraram grande volume de matérias e cartas. Mesmo com o declarado déficit de 10 mil profissionais de educação, a Secretária Estadual de Educação, Darcília Leite, rebateu as críticas atribuindo o problema à falta de gestão eficiente por parte das escolas (BERTA, 2003). Dentre as cartas contrárias, a maioria teve como principal argumento o repúdio ao fundamentalismo.

O ano de 2004 começou com a realização do concurso público para professores de religião, no dia 4 de janeiro. De um total de 3.064 inscritos, foram aprovados 1.299. Porém, só os 500 primeiros puderam ocupar as vagas. Estes se somaram aos 385 docentes que já exerciam a função de professores de ensino religioso no estado.

Em 09/05/04, uma matéria (MENEZES, 2004) registrava que os 31 professores contratados para lecionar em Campos dos Goytacazes (cidade de origem de Rosinha e Anthony Garotinho e seu principal reduto eleitoral) confirmaram que ensinariam em suas aulas os princípios criacionistas. Para integrantes desse grupo o ensino religioso estaria indo, portanto, além do seu caráter confessional, pretendendo substituir ou ao menos rivalizar com os conteúdos das disciplinas escolares de caráter científico, especialmente Biologia e Ciências. Na mesma reportagem, um dos professores, Jeová Ferreira, de 33 anos, garantia que não evangelizaria os alunos, mas transmitiria conhecimento sobre sua religião. Segundo ele o Criacionismo seria ensinado como mais uma corrente de pensamento: "Não será uma imposição, ao contrário do evolucionismo, que é ensinado nas escolas como teoria científica. Os alunos têm direito de conhecer as diferentes correntes de pensamento" (MENEZES, 2004, p. 27). O professor, que até os 23 anos era católico e agora era evangélico, resumiu assim, na mesma reportagem, sua descrença na teoria da evolução das espécies: "Pode botar aí: tenho certeza de que minha avó não era macaca" (MENEZES, 2004, p. 27). As reações não tardaram entre os leitores, sendo em sua maioria críticas às visões fundamentalistas da sociedade e favoráveis à defesa da atividade científica dessas ingerências indevidas.

Em 2005 continuaram a repercutir os acontecimentos do ano anterior, sendo mantido o teor das críticas. Para tal, basta atentar para o teor das manchetes dos editoriais ao longo desse ano: Entre crer e saber (FERNANDES, 2005), Fé frágil e obscurantismo no Rio (BESSERMAN, 2005) e Só faltam a inquisição e o óleo fervente (MINC, 2005) e Fundamentalismo religioso no Rio (LANDIM; MOREIRA, 2005), assinado pelo presidente da União das Sociedades Espíritas do Rio de Janeiro. As cartas dos leitores seguiram a mesma linha de indignação de 2004. É curioso perceber que desde que se multiplicaram as críticas ao criacionismo e ao literalismo bíblico não houve qualquer comentário nos editoriais dos membros da arquidiocese a respeito da questão, seja para defendê-la ou criticá-la.

\section{O ensino religioso no Rio de Janeiro e o debate entre o criacionismo versus evolucionismo}

As opiniões explicitadas em muitas cartas sugerem-nos que a instituição de uma rede discursiva encaminha e influencia o debate, conforme assinala Fry (2005) em seu artigo. O estudo desta rede dá visibilidade ao processo de elaboração e implantação da lei expondo, dentro do possível, as negociações e as disputas que se deram ao longo de todo o período. Assim, tal estudo permite compreender que o confronto das ideias acerca do ensino religioso nas escolas suscitou posicionamentos e revisões de pontos de vistas, a identificação dos protagonistas di- 
retos e indiretos e o levantamento de diversas questões que não faziam parte da agenda inicial da tramitação da lei, como a questão do criacionismo.

É sintomático perceber que a forma como são estruturadas as matérias do jornal, seu enfoque e frequência, acabam por assumir um papel de destaque na condução dessa rede discursiva, resultando em participação maior ou menor dos leitores, em uma direção ou outra, a ponto de fazer praticamente desaparecer, em um segundo momento, o protagonismo católico no projeto de ensino confessional.

As justificativas atuais para o ensino religioso envolvem, como em épocas anteriores, apelos à remissão moral da juventude em um cenário de desagregação social e moral cujo vazio é atribuído, dentre outros fatores, à educação laica. Sobre esse ponto concordam os principais defensores do projeto de ensino confessional adotado no Estado do Rio de Janeiro. Alguns deles, em especial os evangélicos conservadores, vão além, defendendo uma interpretação literal dos textos bíblicos e, como consequência, opondo-se ao ensino dos conteúdos relacionados à evolução e adotando voluntariamente o ensino do criacionismo como explicação para a origem de toda a diversidade biológica.

Expressão emblemática dessa nova fase do embate entre ensino religioso e laicidade na escola pública, a governadora Rosinha Mateus justificou o ensino do criacionismo nas escolas estaduais: "Não acredito na evolução das espécies. Tudo isso é teoria" (MENEZES, 2004, p. 27). Na mesma entrevista ela prossegue dizendo que “... os macacos não se ajoelham para orar".

Posicionamentos como esses revelam que a questão do ensino religioso nas escolas públicas não pode ser pensada mais apenas no âmbito das contradições legais que atentam contra a laicidade. Em meio ao processo de implantação do ensino religioso nas escolas do estado do Rio de Janeiro, esta declaração introduziu um novo elemento à presença da religião na esfera pública, passando agora a associar a introdução de conteúdos religiosos ao ensino de Ciências e Biologia, em uma ingerência ainda mais direta sobre o campo da educação. Como afirma Martins (2004, p. 1)

[...] quem acompanha os desdobramentos da posição do governo fluminense quanto às diretrizes educacionais do estado, sabe que o pronunciamento da governadora possui implicações mais complexas. Ele expressa o fortalecimento de algumas tendências religiosas que vêm ocupando um espaço cada vez mais amplo em diferentes níveis institucionais da sociedade.

Dentre as "implicações mais complexas" a que se refere Martins, o debate sobre o ensino religioso passou, então, a incidir sobre a seleção dos conteúdos e métodos do ensino de Ciências e Biologia. Isto porque a interferência política do Estado assume uma forma de coerção sobre os processos decisórios docentes no tratamento dos conteúdos de evolução no cotidiano escolar. O debate entre criacionismo e evolucionismo passa então explicitamente a ter um caráter institucionalizado, deixando de se travar apenas no domínio do confronto individualizado de ideias, entre professores e seus alunos.

Localizado no ensino de Ciências e Biologia, o tratamento da evolução passa à condição de facultativo, pois professores cujas crenças conflitam-se com esta teoria podem negar o seu ensino, autorizados pelas declarações produzidas nos trâmites da legislação vigente. Em outras palavras, a obrigatoriedade do ensino religioso confessional parece transbordar os terri- 
tórios disciplinares, pois os conteúdos relativos à origem e evolução humana são disputados no currículo da Educação Básica como se as bases teóricas e religiosas que os sustentam fossem equivalentes. Assim, a opção de ensinar evolução desloca-se do âmbito privado e alcança o público, comprometendo a formação do alunado, pois os docentes encontram respaldo para operar seleções que silenciam a explicação biológica. Ainda que este artigo não se proponha a aprofundar os efeitos no ensino e nem disponha de dados que evidenciem o comprometimento da formação do alunado, a ausência (ou o relativismo) do ensino da teoria evolutiva - a mais importante das Ciências Biológicas - obviamente nega aos alunos o direito de acesso a uma das explicações científicas de poder heurístico inquestionável e que tem implicações diretas com a visão de e a inserção no mundo. Ademais, essa negação desqualifica as pesquisas e a literatura acadêmica da área, as quais vêm fertilizando os cursos de formação docente, a elaboração de livros didáticos e a produção curricular não somente no Brasil, como no exterior.

Embora não haja atualmente no Brasil nada que se compare aos movimentos organizados nos Estados Unidos, alguns grupos começaram a se articular, marcando presença em suas escolas confessionais, nas diversas mídias e através de palestras em que alguns de seus representantes percorrem o país. Realizam encontros que procuram emular os formatos de congressos científicos com apresentação de trabalhos e realização de mesas redondas. Vários sítios de igrejas na internet dedicam-se a retransmitir as ideias de algumas das principais vozes do criacionismo, e editoras e revistas vinculadas a denominações religiosas abordam o tema, publicando traduções de livros norte-americanos e de autores nacionais (DORVILLÉ, 2010). É importante destacar uma vez mais que não se trata de posições que se apresentam apenas como manifestações religiosas contrárias à evolução, mas de pretensas argumentações científicas da sua inconsistência. Antes restritos ao interior de denominações religiosas, tais grupos procuram cada vez mais adentrar as escolas e universidades não-confessionais brasileiras. Demonstrando o quanto o tema criacionismo se faz presente hoje na realidade de nosso país, o mesmo foi abordado 92 vezes (entre editoriais e respostas de leitores) no Jornal da Ciência, órgão da Sociedade Brasileira para o Progresso da Ciência, no mesmo período de tempo da pesquisa realizada em O Globo. Em várias das reportagens e cartas dos leitores é denunciada a presença cada vez mais ostensiva desse movimento em nosso país, inclusive de sua mais recente roupagem, o Desenho Inteligente (MARTINS, 2001).

A distinção entre esses dois tipos de lógicas distintas, a da Ciência e a da Religião, foi enfatizada por Fischmann (2008). A primeira tem como atividade inerente o dissenso e o debate, em uma busca pela verdade que se renova constantemente a cada descoberta, tendo como motor contínuo a indagação sistemática dos fatos e a adoção de postura crítica diante da possibilidade de conhecer o real. O mundo das religiões, embora possa incorporar aqui e ali, em maior ou menor grau, alguns desses elementos, opera sob uma lógica distinta, "valendose do argumento que apela ao absoluto, ao sobrenatural, invisível e intangível, à revelação e à crença, lançando mão, conforme a religião, da asserção de dogmas e da definição de doutrinas" (FISCHMANN, 2008, p. 47). No nosso ponto de vista, não há nada que impeça a coexistência de ambas as lógicas no sistema de representações e visões de mundo dos diferentes indivíduos, com todos os seus conflitos e inconsistências de natureza pessoal, recapitulando o conceito de Magistérios Não Interferentes proposto por Gould (2002), que defendemos. O problema, nos parece, é a coexistência de ambas nas mesmas instituições e, mais ainda, travando entre si uma disputa feroz em que a lógica da religião invade o espaço das explicações científicas alegando 
operar pelos mesmos princípios. Os efeitos sobre a educação dos estudantes provocam uma diluição das fronteiras que produz confusão de conceitos, simplificações errôneas e empobrecimento de ambas as lógicas.

Reconhecendo a gravidade destas novas configurações, a comunidade científica organizou-se. O presidente da Sociedade Brasileira para o Progresso da Ciência, Prof. Ennio Candotti afirmou: "[O ensino do criacionismo] é propaganda enganosa. É um caso que deveria ser visto como de defesa do consumidor. Os alunos deveriam procurar o Procon" (GAZIR, 2004, p. A16). A entidade emitiu nota em repúdio às "declarações e medidas educacionais do governo do estado do RJ que visam a exposição dos alunos, cuja mente ainda está em formação, a uma doutrina (o criacionismo) que não encontra qualquer respaldo científico" (GAZIR, 2004, p. A16). No mesmo sentido a Sociedade Brasileira de Genética também se pronunciou contra movimentos desse tipo:

O direito a professar uma religião deve coexistir com o direito de todos, independentemente de seu extrato social, condição biológica ou país, a usufruírem não somente os benefícios gerados pela ciência através do desenvolvimento tecnológico, mas também à visão do mundo proporcionada pela ciência. (SOCIEDADE..., 2005).

Associações criacionistas já existem em nosso país há algum tempo. A mais antiga delas, a Sociedade Criacionista Brasileira, começou a atuar em 1972, através da publicação do periódico Folha Criacionista. Outra organização criacionista é a Associação Brasileira para a Pesquisa da Criação (ABPC), fundada em 1979 em Belo Horizonte (DORVILLÉ, 2010). De acordo com Souza (2009) os movimentos criacionistas brasileiros estão começando a se organizar de forma sistemática, o que segundo ele não deveria ser visto como surpreendente dada a frequente associação estreita deles com o proselitismo religioso. A mesma ideia é corroborada por Matzke (2010), para quem, sendo um subproduto do literalismo bíblico protestante de origem norte-americana (ou dele derivado), o criacionismo aparece em qualquer lugar onde esse fundamentalismo se torne popular. Assim, Numbers (2006) afirma que em nenhum lugar na América do Sul o criacionismo avançou tanto nos últimos anos como no Brasil. A ideia de que, como afirmou Gould (2002, p. 103), "essa controvérsia é tão tipicamente americana quanto a torta de maçã e o tio Sam", nos parece definitivamente afastada. Como destacam Cornish-Bowden e Cárdenas (2007, p. 121): “[...] mesmo que a ameaça não tenha ainda se tornado séria em alguns países, como o Chile, não há certeza de que ela não se tornará no futuro: isso já está acontecendo no Brasil, e o tempo para que os biólogos pensem em como lidar com ela é agora, não em alguns anos".

Esse cenário apresenta um potencial de agravamento significativo diante das mais recentes transformações ocorridas no cenário religioso nacional (JACOB et al., 2003) e do que apontam os resultados de pesquisas recentes como a do Datafolha, constatando que 25\% da população não se refere à teoria evolutiva quando explica a origem dos seres humanos, adotando explicações criacionistas de que Deus nos criou da maneira como somos hoje em algum momento nos últimos 10 mil anos. Apenas $8 \%$ dos brasileiros explicam a origem da espécie humana a partir de espécies ancestrais independentemente de uma criação divina direta (DATAFOLHA, 2010). 
Com certeza esse quadro se traduzirá nos próximos anos em uma realidade cada vez mais comum a se somar às demais já enfrentadas por professores de Ciências e Biologia nas salas de aula da educação básica, e mesmo no ensino superior. Para reunir condições para lidar melhor com esse problema é preciso entender esse processo com mais profundidade, investigando com mais detalhe as razões envolvidas no crescimento desse fenômeno no Brasil nos últimos anos, as quais certamente resultam de um quadro multifatorial. Nesse sentido, trabalhos como os de Sepulveda e El-Hani (2004), e El-Hani e Sepulveda (2010) são certamente cada vez mais necessários por permitirem uma maior compreensão do modo como opera o pensamento de alguns desses estudantes e de suas motivações.

Essa tarefa foge ao escopo desse trabalho, mas podemos apontar de antemão dois pontos norteadores iniciais. Concordando com Martins (2013), o primeiro é a necessidade de reforço, por parte de cientistas e professores de Ciências e Biologia, do conjunto de práticas relacionadas à divulgação científica, empregando os mais diversos recursos. O segundo é o de reforçar um entendimento da natureza da atividade científica, procurando caracterizar seus modos de ação, limites e possibilidades, mesmo entendendo todas as dificuldades inerentes à sua demarcação. Ainda que admitamos não ser possível reduzir as disciplinas escolares às científicas (MARANDINO; SELLES; FERREIRA, 2011), não nos cabe secundarizar as Ciências Biológicas como uma das referências norteadoras do ensino de evolução. Nesse sentido, destaca-se a importância das contribuições da Filosofia da Ciência e da História da Ciência. Devidamente informados, os alunos terão mais chances de entender como opera a Ciência, diferenciando-a de outras lógicas e entendendo que a mesma opera a partir de um materialismo metodológico que não deve ser confundido como uma ontologia materialista (SCOTT, 2004). A partir do estudo de exemplos concretos da história de algumas descobertas científicas, os alunos podem entender de modo mais claro que processos estão envolvidos na sua construção e o que não é válido em sua lógica operacional.

Certamente este artigo não tem como pretensão afirmar como o professor deve se posicionar em sala de aula em relação às ideias enumeradas neste artigo, ou como o ensino de biologia pode de fato combater tais aspectos pseudocientíficos, nem tampouco antecipar como a formação de professores de biologia deve incorporar os resultados descritos no presente trabalho, pois correria o risco de se equiparar aos moldes dogmáticos os quais pretende combater. Entretanto, as ameaças provocadas pela onda neoconservadora demandam respostas apoiadas em estudos acadêmicos que subsidiem os posicionamentos políticos nos diversos fóruns aos quais se exige a presença dos educadores. A inclusão do ensino religioso nas Diretrizes Curriculares Nacionais Gerais da Educação Básica (BRASIL, 2013), bem como no texto preliminar das Bases Nacionais Comuns Curriculares ${ }^{11}$ é um dos exemplos que ilustram a abrangência e a pertinência curricular do debate que o artigo se propõe a enfrentar. Tampouco a discussão deste artigo pode deixar de se contrapor ao movimento autointitulado "escola sem partidos", cujas reivindicações incluem a rejeição ao ensino da evolução biológica e a defesa da "liberdade" das famílias e dos alunos acerca deste e de outros conteúdos curriculares, aprofundando a ingerência

\footnotetext{
${ }^{11}$ Disponível em: <http://basenacionalcomum.mec.gov.br>. Acesso em: 14 out. 2016.
} 
do privado na educação pública. Associações científicas ${ }^{12}$ têm enfaticamente se posicionado contra tal estratégia conservadora, em consonância com argumentos elencados neste texto.

Desde a década de 1990, operando em associação ao neoliberalismo - ainda que distinto deste -, o avanço do neoconservadorismo em escala mundial (APPLE, 1994) se refina e se afirma na sociedade brasileira. Em seu artigo, elaborado em 1992 (publicado no Brasil em 1994), Michael Apple antecipa um debate que, naquele momento, talvez tenha parecido descontextualizado à realidade social e política do Brasil. Afinal, vivíamos um período de democratização que pretendia exorcizar os traumas da ditadura e se opunha às armadilhas ideológicas do governo de direita que havia se encerrado, tornando difícil aceitar, na análise do autor, paralelismos com o Brasil, entendendo-a apenas como pertinente à realidade norte-americana. Entretanto, o artigo de Apple contribui para a compreensão dos complexos meandros que formam o que ele denomina de "restauração conservadora" (APPLE, 1994, p. 69) na disputa sobre o controle da escola. De um lado, a ideologia da "economia de mercado" que reduz a ação do estado, recomenda a privatização, a livre escolha e defende o emprego da metodologia empresarial aos professores e alunos, exaltando a competição e produzindo rankings, por meio da vinculação direta entre currículo mínimo e sistema de avaliação. De outro lado, o neoconservadorismo requer um estado forte para agir sobre o controle dos sujeitos, defendendo a "liberdade", desde que sejam reforçados os valores da família e da religião, sob o argumento de recuperação moral da sociedade. No Brasil, a emergência de políticas de currículo e de avaliação que têm assolado a comunidade educacional nas últimas duas décadas, bem como a ameaça à autonomia docente e a crescente ingerência de interesses privados e conservadores como o "movimento escola sem partido", o combate ao que é intencionalmente denominado ideologia de gênero e a defesa da narrativa criacionista em oposição ao ensino de evolução nas aulas de Ciências e Biologia demonstram a atualidade da análise de Apple. Sem dúvida, cabe à comunidade acadêmica se posicionar criticamente. Ao sugerir a persistência do conservadorismo que se reinventa, o artigo se coloca ao lado do compromisso de fornecer elementos que qualifiquem o debate em bases políticas e acadêmicas.

\footnotetext{
${ }^{12}$ Dentre elas, destacamos o manifesto e a moção de repúdio votada na Assembleia Geral da Associação Brasileira de Pesquisa em Educação em Ciências (ABRAPEC) no X ENPEC realizado em novembro de 2015. De igual modo, o posicionamento da Associação Nacional de Pesquisadores Universitários de História expressa sua oposição ao "movimento escola sem partidos". Disponível em: <https://dl.dropboxusercontent. $\mathrm{com} / \mathrm{u} / 34634009 /$ Carta $\% 20 \mathrm{de} \% 20$ Rep $\%$ C3\%BAdio\%20ESP.pdf $>$. Acesso em: 14 out. 2016.
} 
Ensino religioso nas escolas estaduais do Rio de Janeiro: ...

\section{Referências}

APPLE, M. A política do conhecimento oficial: faz sentido a ideia de um currículo nacional? In: MOREIRA, A. F. B.; SILVA, T. T. Currículo, cultura e sociedade. São Paulo: Cortez, 1994. p. 59-91.

BERTA, R. Novos professores só para o ensino religioso. O Globo, Rio de Janeiro, 26 ago. 2003.

BESSERMAN, S. Fé frágil e obscurantismo no Rio. O Globo, Rio de Janeiro, 1 abr. 2005.

BRASIL. Ministério da Educação. Diretrizes curriculares nacionais da educação básica. Brasília, 2013. Disponível em: < http://portal.mec.gov.br/index.php?option=com_ docman\&view $=$ download\&alias $=15548-d-c-n-e d u c a c a o-$ basica-nova-pdf\&Itemid $=30192>$. Acesso em: 14 out. 2016.

CARNEIRO, S. S.; CONTINS, M. Religião nas escolas: comparação entre Brasil e EUA. In: REUNIÃO BRASILEIRA DE ANTROPOLOGIA, 25., 2006, Goiânia. Anais... Goiânia: SBA, 2006. 1 CD-ROM.

CAVALIERI, A. M. O mal-estar do ensino religioso nas escolas públicas. Cadernos de Pesquisa, São Paulo, v. 37, n. 131, p. 303-332, 2007. Disponível em: < http://dx.doi. org/10.1590/S0100-15742007000200005>. Acesso em: 14 out. 2016.

CORNISH-BOWDEN, A.; CÁRDENAS, M. The threat from creationism to the rational teaching of biology. Biological Research, Santiago, v. 40, n. 2, p. 113-122, 2007. Disponível em: <http://dx.doi.org/10.4067/S0716-97602007000200002>. Acesso em: 14 out. 2016.

CUNHA, L. A. Autonomização do campo educacional: efeitos do e no ensino religioso. Revista Contemporânea de Educação, Rio de Janeiro, n. 1, p. 1-15, 2006.

O Estado do Rio de Janeiro e o ensino religioso na educação pública: a experiência dos municípios de Duque de Caxias e Petrópolis. Notandum, São Paulo, n. 15, p. 17-21, 2012 .

CURY, C. R. J. Ensino religioso na escola pública: o retorno de uma polêmica recorrente. Revista Brasileira de Educação, Rio de Janeiro, n. 27, p. 183-191, 2004. Disponível em: <http://dx.doi.org/10.1590/S1413-24782004000300013>. Acesso em: 14 out. 2016.

DATAFOLHA. Pesquisa de opinião pública sobre o criacionismo. Folha de São Paulo, São Paulo, n. 29.584, 2 abr. 2010.

DAVILA, J. Diploma de brancura. São Paulo: Ed. UNESP, 2006.

DORVILLÉ, L. F. M. Religião, escola e ciência: conflitos e tensões nas visões de mundo de alunos de uma licenciatura em ciências biológicas. 2010. 357 f. Tese (Doutorado) Universidade Federal Fluminense, Niterói, 2010.

EL-HANI, C. N.; SEPULVEDA, C. The relationship between science and religion in the education of protestant biology preservice teachers in a brazilian university. Cultural Studies of Science Education, Dordrecht, v. 5, n. 1, p. 103-125, 2010.

FERNANDES, R. Entre crer e saber. O Globo, Rio de Janeiro, 24 ago. 2005. 
FISCHMANN, R. Ciência, tolerância e Estado laico. Ciência e Cultura, São Paulo, v. 60, n. esp., p. 42-50, 2008.

FRY, P. O significado da anemia falciforme no contexto da "política" racial do governo brasileiro, 1995-2004. História, Ciências, Saúde-Manguinhos, Rio de Janeiro, v. 12, n. 2, 2005. Disponível em: <http://dx.doi.org/10.1590/S0104-59702005000200007>. Acesso em: 14 out. 2016.

GASPARI, E. A fpilantropia e o atraso riram por último. Folha de São Paulo, São Paulo, 16 jan. 2000. Brasil, p. 14.

GAZIR, A. Escolas do Rio vão ensinar criacionismo. Folha de São Paulo, São Paulo, 13 maio 2004. Caderno Ciência, p. A16.

GIANNOTTI, J. A. Senso religioso e contra-senso político. O Globo, Rio de Janeiro, 16 maio 1997. Opinião, p. 7.

GIUMBELLI, E.; CARNEIRO, S. S. Introdução. In: ENSINO religioso no Estado do Rio de Janeiro: registros e controvérsias. Rio de Janeiro: ISER, 2004. p. 11-19. (Comunicações, $60)$.

GOMES, A. S. Sobre a necessidade de um Estado laico. O Globo, Rio de Janeiro, 11 jan. 1999.

GOULD, S. J. Pilares do tempo. São Paulo: Rocco, 2002.

HERINGER, J. Ensino religioso. O Globo, Rio de Janeiro, 24 maio 1997. Cartas dos leitores, p. 6.

HIDALGO, L.; BERTOL, R. Projeto de lei obriga leitura da Bíblia. O Globo, Rio de Janeiro, 22 mar. 2002. p. 19.

HORTAL, J. Dever do Estado. O Globo, Rio de Janeiro, 14 mar. 2002.

JACOB, C. R. et al. Atlas da filiação religiosa e indicadores sociais no Brasil. Rio de Janeiro: Ed. PUC-Rio; São Paulo: Loyola, 2003.

KAMEL, A. Diversidade. O Globo, Rio de Janeiro, 11 jan. 1999. Editorial, p. 6.

KITTLER, F. A. Discourse networks, 1800/1900. Stanford: Stanford University Press, 1990.

LANDIM, M. I. P. F.; MOREIRA, C. L. R. Fundamentalismo religioso no Rio. O Globo, Rio de Janeiro, 17 fev. 2005. Opinião, p. 7.

LARSON, E. J. Trial and error: the American controversy over creation and evolution. Oxford: Oxford University Press, 2003.

MAFRA, C. Os evangélicos. Rio de Janeiro: Jorge Zahar, 2001.

MARANDINO, M.; SELLES, S. E.; FERREIRA, M. S. Ensino de biologia: histórias e práticas em diferentes espaços educativos. São Paulo: Cortez, 2011. 
MARTINS, M. V. O criacionismo chega às escolas do Rio de Janeiro: uma abordagem sociológica. ComCiência, São Paulo, n. 56, 2004.

. De Darwin, de caixas-pretas e do surpreendente retorno do criacionismo. História, Ciências, Saúde-Manguinhos, Rio de Janeiro, v. 8, n 3, p. 739-756, 2001. Disponível em: <http://dx.doi.org/10.1590/S0104-59702001000400013>. Acesso em: 14 out. 2016.

. Quando uma sociologia da ciência se faz necessária: aspectos contemporâneos do embate entre criacionistas e evolucionistas. Filosofia e História da Biologia, Ribeirão Preto, v. 8, n. 2, 279-299, 2013.

MATHEUS, L. Igrejas querem mudar lei do ensino de religião. O Globo, Rio de Janeiro, 14 out. 2000. p. 15.

MATZKE, N. J. The evolution of creationist movements. Evolution: education and outreach, Heidelberg, v. 3, n. 2, p. 145-162, 2010.

MENDONÇA, A. A. Religião na escola: registros e polêmicas na rede estadual do Rio de Janeiro. 1012. 125 f. Dissertação (Mestrado) - Universidade Federal do Rio de Janeiro, Rio de Janeiro, 2012.

MENEZES, M. Polêmica sobre criacionismo chega às escolas. O Globo, Rio de Janeiro, 9 maio 2004. p. 27.

MINC, C. Só faltam a inquisição e o óleo fervente. O Globo, Rio de Janeiro, 1 abr. 2005.

NUMBERS, R. L. The creationists: from scientific creationism to intelligent design.

Massachusetts: Harvard University Press, 2006.

PESSOA, F. Novo arcebispo visita Garotinho e deputados. O Globo, Rio de Janeiro, 25 set. 2001.

PRADO, L. A. Ensino religioso e a Constituição. O Globo, Rio de Janeiro, 2 jun. 1997. Opinião, p. 7.

SALES, E. A. Dominus Jesus. O Globo, Rio de Janeiro, 16 set. 2000. Opinião, p. 7.

. Educação cristã. O Globo, Rio de Janeiro, 14 set. 2002.

. Educar para salvar. O Globo, Rio de Janeiro, 28 jun. 1997. Opinião, p. 7.

SANTORO, F. Religião na escola pública. O Globo, Rio de Janeiro, 3 nov. 2000.

SCOTT, E. C. Evolution versus creationism: an introduction. Berkeley: University of California Press, 2004.

SEPULVEDA, C. A. S.; EL-HANI, C. N. Quando visões de mundo se encontram: religião e ciência na trajetória de formação de alunos protestantes de uma licenciatura em ciências biológicas. Investigações em Ensino de Ciências, Porto Alegre, v. 9, n. 2, p. 137-175, 2004. 
SOCIEDADE Brasileira de Genética se manifesta contra criacionismo. Jornal da Ciência, São Paulo, n. 2761, 5 maio 2005. Disponível em: <http://www.jornaldaciencia.org.br/ edicoes/?url=http://jcnoticias.jornaldaciencia.org.br/sociedade-brasileira-de-genetica-semanifesta-contra-criacionismo/>. Acesso em: 14 out. 2016.

SOUZA, S. A goleada de Darwin: sobre o debate criacionismo / darwinismo. Rio de Janeiro: Record, 2009.

TAVES, R. F. Conselho decide hoje sobre ensino religioso. O Globo, Rio de Janeiro, 3 nov. 1998.

VEIGA, E.; BRANDÃO, R. Teoria da evolução não é incompatível com fé, diz Papa. O Estado de São Paulo, São Paulo, 29 out. 2014. p. 22.

VILHENA, J. Ensino de religião deverá ter visão ecumênica. O Globo, Rio de Janeiro, 16 set. 2000. p. 21.

Artigo recebido em 24/11/2014. Aceito em 16/09/2015.

Endereço para contato: Universidade Federal Fluminense, Faculdade de Educação, Departamento Sociedade, Educação e Conhecimento, CEP 24346-040, Niterói, RJ, Brasil. 